\title{
DIRATTOS HUMANOS NA ATUAÇÃO DE PSICÓlogos NA SOCIOEDUCAÇÃO
}

\section{Bianca Zanchi Machado}

Universidade Federal de Santa Maria (UFSM)

Samara Silva dos Santos

Universidade Federal de Santa Maria (UFSM)
Recebido em: 27/02/2020

$1^{\text {a }}$ revisão em: 15/11/2020

Aceito em: 21/01/2021

\section{RESUMO}

O estudo tem como objetivo investigar como a medida socioeducativa - MSE, na concepção dos profissionais participantes, vem influenciando na proteção e promoção dos direitos dos adolescentes em cumprimento de medida socioeducativa. Foram realizadas entrevistas semiestruturadas com seis psicólogos que trabalham com MSE. As entrevistas foram transcritas e analisadas qualitativamente. As respostas revelam o aspecto negativo das concepções socioculturais e das informações midiáticas sobre o adolescente em MSE, configurando inclusive em um desserviço ao desenvolvimento das Medidas de forma que impactam em desarticulações na rede de atendimento e inflam os preconceitos sociais. Quanto às garantias de direitos analisou-se pontos como: estrutura física, acesso à educação, respeito às individualidades dos adolescentes e acesso aos serviços básicos de saúde e assistência. Destaca-se a relevância de investir em capacitações para os profissionais não somente do sistema socioeducativo, mas de todas as políticas que devem assistir os adolescentes em cumprimento de MSE.

Palavras-chave: medida socioeducativa; direitos humanos; concepções socioculturais; adolescente em cumprimento de medida socioeducativa. 


\section{HUMAN RIGHTS IN THE PRACTICE OF PSYCHOLOGISTS IN SOCIO-EDUCATION}

The study aims to investigate as a socio-educational measure - MSE, in the conception of participating professionals, which influences the protection and promotion of the rights of adolescents in compliance with socio-educational measure. Semi-structured interviews were conducted with six psychologists who work with MSE. The interviews were transcribed and analyzed qualitatively. The answers reveal the negative aspect of socio-cultural conceptions and media information about the adolescent in MSE, which also constitutes a disservice to the development of Measures in a way that impacts disarticulations in the service network and inflames social prejudices. As for the guarantee of rights, points were analyzed such as: physical structure, access to education, respect for the adolescents' individualities and access to basic health and assistance services. The relevance of investing in training for professionals is highlighted, not only from the socio-educational system, but from all policies that should assist adolescents in compliance with MSE.

Keywords: socio-educational measure; human rights; sociocultural conceptions; adolescent in compliance with socio-educational measure. 


\section{LOS DERECHOS HUMANOS EN EL DESEMPEÑO DE LOS PSICÓLOGOS EN SOCIOEDUCACIÓN}

\section{RESUMEN}

El estudio tiene como objetivo investigar cómo la medida socioeducativa - MSE, en opinión de los profesionales participantes, ha influido en la protección y promoción de los derechos de los adolescentes en cumplimiento de la medida socioeducativa. Se realizaron entrevistas semiestructuradas con seis psicólogos que trabajan con MSE. Las entrevistas fueron transcritas y analizadas cualitativamente. Las respuestas revelan el aspecto negativo de las concepciones socioculturales y la información de los medios sobre los adolescentes en MSE, configurar incluso un perjuicio para el desarrollo de las Medidas de manera que afecte las interrupciones en la red de servicios e infla los prejuicios sociales. En cuanto a las garantías de derechos, se analizaron puntos como: estructura física, acceso a la educación, respeto a las individualidades de los adolescentes y acceso a servicios básicos de salud y asistencia. Se destaca la importancia de invertir en capacitación para profesionales, no solo desde el sistema socioeducativo, sino desde todas las políticas que deberían ayudar a los adolescentes a cumplir con las MSE.

Palabras clave: medida socioeducativa; derechos humanos; concepciones socioculturales, adolescentes en cumplimiento de la medida socioeducativa. 


\section{INTRODUÇÃO}

As medidas socioeducativas (MSE) foram instituídas a partir do Estatuto da Criança e do Adolescente - ECA (Presidência da República, 1990) e regulamentadas de forma mais pormenorizada com o Sistema Nacional de Atendimento Socioeducativo - Sinase (Presidência da República, 2012). As mesmas são aplicadas aos adolescentes entre doze e dezoito anos em razão de atos infracionais praticados, os quais são definidos como a conduta descrita como crime ou contravenção penal. As medidas são aplicadas pelas autoridades competentes que definem o tipo de MSE a ser cumprida, podendo ser: advertência, obrigação de reparar o dano, prestação de serviço à comunidade, liberdade assistida, inserção em regime de semiliberdade e internação em estabelecimento educacional. A medida aplicada ao adolescente deverá levar em conta a sua capacidade de cumpri-la, as circunstâncias e a gravidade da infração (Presidência da República, 1990).

O Sinase busca promover e respeitar os direitos dos sujeitos inseridos no seu sistema, independentemente do tipo de MSE a ser cumprida. Um dos seus primeiros objetivos é a integração social do adolescente e a garantia de seus direitos individuais e sociais, por meio do cumprimento de seu plano individual de atendimento (Presidência da República, 2012). Além disso, tal documento visa garantir também outros direitos individuais (para além dos já garantidos em outras legislações), como:

I - ser acompanhado por seus pais ou responsável e por seu defensor, em qualquer fase do procedimento administrativo ou judicial; II - ser incluído em programa de meio aberto quando inexistir vaga para o cumprimento de medida de privação da liberdade, exceto nos casos de ato infracional cometido mediante grave ameaça ou violência à pessoa, quando o adolescente deverá ser internado em Unidade mais próxima de seu local de residência; III - ser respeitado em sua personalidade, intimidade, liberdade de pensamento e religião e em todos os direitos não expressamente limitados na sentença; IV - peticionar, por escrito ou verbalmente, diretamente a qualquer autoridade ou órgão público, devendo, obrigatoriamente, ser respondido em até 15 (quinze) dias; V ser informado, inclusive por escrito, das normas de organização e funcionamento do programa de atendimento e também das previsões de natureza disciplinar; VI - receber, sempre que solicitar, informações sobre a evolução de seu plano individual, participando, obrigatoriamente, de sua elaboração e, se for o caso, reavaliação; VII - receber assistência integral à sua saúde, conforme o disposto no art. 60 desta Lei; e VIII - ter atendimento garantido em creche e pré-escola aos filhos de 0 (zero) a 5 (cinco) anos (Presidência da República, 2012, p. 11). 
Todavia, algumas pesquisas e relatórios vêm apontando que muitas são as violações de direitos e práticas violentas que acontecem dentro de instituições que executam essas medidas (Conselho Nacional do Ministério Público [CNMP], 2013; Paiva, Gomes, \& Valença, 2016). Pensando sobre os requisitos para funcionamento de unidades de internação, por exemplo, tem-se: o quesito salubridade, que diz respeito às questões de higiene e conservação, iluminação e ventilação adequadas em todos os espaços da unidade, na maioria dos estados as unidades não atingiram $50 \%$ de aprovação neste quesito. Quanto às salas de aula das unidades, em todas as regiões brasileiras foram encontradas unidades de internação com salas de aula inadequadas, julgada a inadequação a partir dos parâmetros equipamentos, iluminação e suporte de biblioteca. Além disso, segundo dados de março de 2013, em mais de $80 \%$ das unidades no país não há atendimento aos egressos e a suas famílias pela equipe técnica da unidade (CNMP, 2013). O estudo de Paiva et al. (2016) traz como exemplo uma Unidade Socioeducativa na qual nas denúncias apontavam atos de violência que chegaram a resultar na morte de um adolescente, atos de torturas e tratamentos cruéis, desumanos e degradantes; isolamento prolongado e até supostos abusos sexuais.

Dados esses que são bastante distintos do que é veiculado na mídia, nas redes sociais e na sociedade no geral (de que os adolescentes que cumprem MSE não são responsabilizados de fato, o que deixa uma distorcida ideia de que as instituições que executam tais medidas não o fazem com severidade). Ou seja, dificilmente há reportagens que denunciam o tratamento desumano recebido por estes jovens em algumas instituições. Facilmente, é possível identificar nas notícias a ideia de que é necessário um recrudescimento das MSE, pois os atos infracionais praticados por adolescentes são um dos grandes agravantes das estatísticas de violência quando, na verdade, tem um impacto bem menos significativo nesses dados (Petry \& Nascimento, 2016; Secretaria Especial de Direitos Humanos [SEDH] \& Fundo Das Nações Unidas [UNICEF], 2009). Alguns indícios acerca do impacto quantitativo dos crimes praticados por adolescentes são apresentados pela SEDH e pelo UNICEF, em material publicado em 2009, o qual apontou resumidamente que em 2004 os adolescentes representavam 15\% da população. Dentro disso, o número de adolescentes em cumprimento de medidas socioeducativas não atingia $1 \%$ do universo da população adolescente. Além disso, no estado de São Paulo no ano de 2003 os adolescentes foram responsáveis por menos de $4 \%$ dos crimes cometidos. Diante de tais dados não é possível afirmar que o maior problema da violência no país advenha da população adolescente. População essa que não deveria estar sendo exposta como problema social, mas sendo preservada enquanto cidadão de direitos em desenvolvimento.

Quanto aos direitos, é pertinente lembrar que a Declaração Universal dos Direitos Humanos - DUDH (da qual o Brasil é signatário) já completou setenta anos de existência. Mas, ainda hoje, enfrentam-se dificuldades na tarefa de garantir esses direitos a todos os cidadãos. Nos discursos que atacam os direitos humanos são 
recorrentes argumentos que demonstram desconhecimento do que sejam de fato os direitos humanos, sua abrangência e importância, pois reproduzem ideias similares a de que os direitos humanos são para proteger bandidos, por exemplo.

Pensando nos direitos dos jovens em situação de cumprimento de MSE, toma-se, por exemplo, o quinto artigo da DUDH: "Ninguém será submetido à tortura nem a tratamento ou castigo cruel, desumano ou degradante" (Organização das Nações Unidas [ONU], 1948). Para refletir o quanto ainda esse direito é violado na prática é necessário destacar e explorar os resultados do estudo de Petry e Nascimento (2016), no qual pode-se identificar que determinado grupo de uma rede social de grande alcance vem apresentando prescrições de violência e repressão destinadas aos jovens que cometem ato infracional. As prescrições de violência do mundo virtual chegam ao próprio contexto de cumprimento de MSE. Inspeções realizadas em instituições que executam MSE nas quais foram detectadas diferentes formas de violência e negligência por parte daqueles que deveriam estar garantindo e zelando pelo bem-estar dos adolescentes ali inseridos (CNMP, 2013; Conselho Federal de Psicologia [CFP], 2006).

O tema da redução da maioridade penal tem algum espaço neste contexto. A discussão a respeito da diminuição da redução da maioridade penal não chega a ser um assunto novo. Sua primeira proposta de emenda constitucional data do ano de 1993 (Proposta de Emenda à Constituição [PEC] n¹71/1993), a qual chegou a ser votada e aprovada no ano de 2015 , tendo sido então encaminhada para apreciação do Senado (PEC n¹15/2015). A partir do que propõe tal projeto, a ideia de proteção integral, preconizada pelo ECA, é desconsiderada e o direito penal torna-se aclamado como a panaceia da segurança pública (Silva Junior $\&$ Garcia, 2017). As ideias apresentadas neste tipo de proposta resultam de uma ideologizada visão da junção entre violência e crise social (e o envolvimento de jovens com atos infracionais) e instrumentaliza o senso comum, com apoio da mídia, divulgando e reforçando a ideia de que o enfrentamento a tais situações é uma questão de segurança pública e repressão policial (Cruz Neto \& Moreira, 1999). Dessa forma, o fenômeno que deveria ser tratado em último caso pelo olhar da segurança pública, acaba tendo o mesmo como primeiro e único meio de análise.

A postura dos grupos que defendem a redução da maioridade penal revela uma mentalidade que privilegia a punição e a segregação em detrimento à proteção social e à garantia e defesa de direitos (Ministério do Desenvolvimento Social e Agrário $[M D S A], 2016)$. Partindo das legislações aqui apontadas e ainda nos aspectos históricos, sociais e psicológicos que estão envolvidos nas vivências desses jovens que se envolveram em atos infracionais é que se confrontam tais ideias pró redução da maioridade penal (Valença, Lima, \& Paiva, 2014).

Os discursos pró redução da maioridade penal vêm de encontro ao que prima a legislação brasileira nesse sentido. A começar pela Constituição Brasileira de 1988 que trouxe a compreensão de crianças e adolescentes como uma das prioridades 
do Estado brasileiro, pactuando responsabilidades junto aos diferentes segmentos sociais com vistas à proteção dessa população. E a partir da Emenda Constitucional 65/2010, o artigo 227 da Constituição passa a assim colocar:

É dever da família, da sociedade e do Estado assegurar à criança, ao adolescente e ao jovem, com absoluta prioridade, o direito à vida, à saúde, à alimentação, à educação, ao lazer, à profissionalização, à cultura, à dignidade, ao respeito, à liberdade e à convivência familiar e comunitária, além de coloca-los a salvo de toda forma de negligência, discriminação, exploração, violência, crueldade e opressão (Presidência da República, 2010).

Além disso, internacionalmente, em 1989 teve-se a Convenção sobre os Direitos da Criança, que foi ratificada pelo Brasil no ano de 1990 e que destaca que "criança é todo o ser humano menor de 18 anos, salvo se, nos termos da lei que Ihe for aplicável, atingir a maioridade mais cedo" (ONU, 1959). Outro documento legal é o ECA do ano de 1990, o qual assegura proteção aos direitos da população infantojuvenil, o seu terceiro artigo apresenta que:

A criança e o adolescente gozam de todos os direitos fundamentais inerentes à pessoa humana, sem prejuízo da proteção integral de que trata esta Lei, assegurando-se-lhes, por lei ou por outros meios, todas as oportunidades e facilidades, a fim de lhes facultar o desenvolvimento físico, mental, moral, espiritual e social, em condições de liberdade e de dignidade (Presidência da República, 1990, p. 1).

Com isso, fica claro que muitas são as legislações que defendem os direitos das crianças e adolescentes nestes termos e reafirmam o entendimento de que antes de atingir os dezoito anos de idade os sujeitos ainda não têm o entendimento necessário sobre as atitudes tomadas e assim não devem ser punidos como se o tivessem. Mas devem ser responsabilizados de acordo com a gravidade do ato cometido, inclusive como forma de aprender sobre a dimensão da atitude tomada e das consequências, tendo assim, uma possibilidade de ressignificar as atitudes tomadas, o caminho seguido até ali e aprender algo com esse acontecimento. Em nota técnica a respeito da redução da maioridade penal o Instituto de Pesquisa Econômica Aplicada ([IPEA], 2015) argumenta que:

O caminho para combater a violência e a criminalidade entre os jovens deveria ser a promoção dos direitos fundamentais, como o direito à vida, e dos direitos sociais preconizados na Constituição e no ECA, de educação, profissionalização, saúde, esporte, cultura, lazer, e viver em família (p. 12).

Logo, é relevante dizer que pode ser mais eficiente investir em estratégias de prevenção à violação de direitos e de promoção dos direitos fundamentais, pela via da educação, por exemplo. Oportunizar que os jovens tenham acesso a saúde, 
a educação e profissionalização pode evitar que os mesmos se exponham a situações de risco. O que pode evitar a necessidade de intervenções do Estado com vistas a corrigir ausências ou de maiores investimentos em políticas que visem punição ou coerção. Quer dizer, investir na prevenção e promoção ao invés de precisar intervir quando os problemas estão já colocados.

Entretanto, sabe-se que existem dificuldades ainda enfrentadas na execução da política socioeducativa, o que pode acabar tornando complexa a tarefa de garantir os direitos desses adolescentes. Sobre as dificuldades enfrentadas, é inevitável considerar o peso dessa ideia ainda presente do "menorismo", entendido como essa mentalidade que emana de uma concepção de mundo de cidadania limitada, vigiada, dividida entre crianças e menores e que garante direitos para umas e determinado assistencialismos e repressão aos outros (Zamora, 2014).

Além disso, a política socioeducativa acaba tendo seu trabalho setorializado, contando com diferentes níveis de gestão que nem sempre dialogam, sendo as de caráter fechado e semiliberdade geridas a nível estatal e as MSE de caráter aberto de gestão municipal, de acordo com o estabelecido no Sinase (Presidência da República, 2012). Essas gestões devem seguir uma homogeneidade quanto aos objetivos e seus preceitos e também dialogar nas situações de jovens reincidentes e aqueles que eventualmente mudam de regime de MSE. O Sinase, enquanto sistema integrado, articula os três níveis de governo para o desenvolvimento desses programas de atendimento, considerando a intersetorialidade e a co-responsabilidade da família, comunidade e Estado (Conselho Nacional dos Direitos da Criança e do Adolescente [CONANDA], 2006). Também, é de suma importância o diálogo com as outras políticas, como saúde, educação e assistência social visando a um atendimento integral a essa população. Tal articulação demanda muito dos trabalhadores, demanda também conhecimentos diversos sobre as políticas sociais e os funcionamentos de cada equipamento da rede, além de conhecimento acerca dos direitos desses jovens para poder saber onde buscar tais garantias.

Com o advento das políticas sociais no Brasil, há a situação de que os psicólogos, que não vinham recebendo formações específicas e também não estavam habituados a uma reflexão crítica sobre a dinâmica social brasileira, repentinamente são colocados diante do trabalho nessas políticas (Silva, 2005). A partir dessa preocupação, o Conselho Federal de Psicologia construiu no ano de 2003 uma cartilha intitulada "Os Direitos Humanos na Prática Profissional dos Psicólogos". Na qual busca-se responder a um importante questionamento: "Até que pontos os psicólogos se identificam com a ampliação dos direitos e das autonomias dos sujeitos e dos grupos sociais e, até que ponto eles se colocam na contramão, suscitando o preconceito, patrocinando a discriminação e mantendo o status quo?" (CFP, 2003, p. 6). 
Mello (1999) problematiza que a formação em psicologia sempre foi bastante centrada na formação técnica, baseada em testes e formas de terapia e intervenção. Isso é uma base importante e que caracteriza a atuação nessa área. Porém, a partir da expansão do campo de atuação da psicologia para áreas que envolvem o trabalho com setores mais amplos da sociedade, é necessário pensar a reformulação dos currículos e a ampliação da reflexão crítica sobre os parâmetros usados. "Enquanto um direito formal não se transforma em direito reconhecido e intersubjetivamente compartilhado, tem-se que lutar por ele, com as armas que a universidade pode nos dar: consciência e conhecimento" (Mello, 1999, p. 150).

O psicólogo é um dos profissionais técnicos que integra as equipes multiprofissionais que trabalham com os jovens que enfrentam conflitos com a lei. Esse profissional deve trabalhar pautado por um compromisso ético, implicando-se com questões sociais e políticas no que tange à MSE, intervindo de forma crítica, tendo como principal tarefa operar prioritariamente quando há ameaça à dignidade humana (CFP, 2010).

O compromisso ético-político do profissional psicólogo, cada vez mais implicado com as temáticas sociais, supõe visão ampliada de sua função e atuação. Isso implica analisar o contexto social, a demanda por sua presença e a contribuição na política de atendimento ao adolescente autor de ato infracional que está em privação de liberdade (CFP, 2010, p. 20).

No que tange a atuação na socioeducação, entende-se que ainda que alguns adolescentes estejam cometendo atos reprováveis e infringindo leis, a maioria das informações disponíveis aponta para um conjunto expressivo de jovens que estão desprotegidos das políticas públicas e dos direitos sociais básicos e são, ainda, vítimas de violência, e não autores, conforme grande parte da sociedade acredita (IPEA, 2015). Nesse sentido, cabe o chamado de atenção para a urgência da construção e manutenção de redes protetivas para esses jovens (todos eles).

Considera-se que a última década foi de conquistas no campo dos direitos da criança e do adolescente, principalmente na área da educação básica e superior, com aumentos significativos no número de matrículas e frequências escolares. Grande parte desses avanços é consequência direta de programas sociais de alcance nacional, voltados para o público jovem, como o Programa Nacional de Acesso ao Ensino Técnico e Emprego (PRONATEC); o Programa Nacional de Inclusão de Jovens (Projovem Urbano); o Programa Universidade para Todos (ProUni); o Programa Nacional de Erradicação do Trabalho Infantil (PETI); entre outros (IPEA, 2015). Entretanto, devido a nova onda de intolerância e crítica a respeito das políticas sociais é preciso manter-se vigilante e buscar conhecer e analisar as políticas existentes. Isso com objetivo de melhorá-las nos aspectos que possam estar inconsistentes e também trazer à tona as boas práticas que vêm sendo realizadas. 
Este estudo teve como objetivo conhecer o entendimento dos participantes, que são psicólogos que trabalham no campo socioeducativo, sobre a articulação que ocorre em sua prática profissional entre direitos humanos e Medidas socioeducativas. Parte-se da seguinte questão: Em que circunstâncias as MSEs, atualmente executadas, influenciam a proteção e promoção de direitos dos adolescentes em cumprimento de MSE e (em que circunstâncias) reforçam a exclusão e o descompromisso como forma de (des)proteção?

\section{MÉTODO}

O estudo aqui apresentado se trata de uma pesquisa qualitativa, descritiva e exploratória. A pesquisa qualitativa para Minayo (1994) é o trabalho com um universo de significados, motivos, aspirações, crenças, valores e atitudes, o que corresponde a um espaço profundo das relações, dos processos e dos fenômenos que não podem ser reduzidos à operacionalização de variáveis. Buscando assim interpretações e significados para o fenômeno. Este estudo integra uma grande pesquisa que envolve três instituições públicas de ensino superior do país - Universidade Federal do Rio Grande do Norte, Universidade de Brasília e Universidade Federal de Santa Maria, por meio do Programa Nacional de Cooperação Acadêmica ([PROCAD] edital 071/2013). A pesquisa proposta visa conhecer sobre a formação e atuação dos psicólogos nas políticas sociais de saúde, assistência social e socioeducação nas três localidades onde situam as instituições participantes. Parte das informações coletadas e analisadas neste artigo compõe a fase de pesquisa sobre o campo da socioeducação realizada pelo núcleo da Universidade Federal de Santa Maria.

\section{PARTICPANTES}

Participaram da pesquisa os seis psicólogos que atuavam com MSE no município naquele momento. Esse número de participantes é a totalidade de Psicólogos que trabalham com a Socioeducação no município no momento em que a pesquisa foi desenvolvida. Os mesmos tinham idade entre 30 e 48 anos, trabalhavam com MSE de caráter fechado (dois participantes), semiliberdade (um participante) e meio aberto (três participantes). Os mesmos possuíam entre 3 meses e 14 anos de atuação com o campo da socioeducação. Todos eles possuíam formação complementar, como especialização (cinco participantes), na área clínica e da saúde e mestrado (um participante).

\section{INSTRUMENTOS}

O instrumento utilizado para a coleta de informações foi a entrevista semiestruturada criada para abarcar a pesquisa supracitada, que envolveu a cooperação acadêmica do PROCAD. Ao roteiro original foram incluídas seis perguntas com enfoque em direitos humanos e em como os profissionais percebiam as MES e o seu trabalho enquanto ferramenta para garantir direitos. Segundo Minayo (1994) a entrevista se caracteriza por uma comunicação verbal 
que reforça a importância da linguagem e do significado da fala e que serve como meio de coleta de informações sobre um determinado tema científico.

O roteiro final da entrevista englobou dados sociodemográficos, seis questões sobre o serviço (local de trabalho) e vinte e sete questões sobre formação, trajetória profissional e atuação na socioeducação e direitos humanos. As entrevistas tiveram duração aproximada de uma hora, foram audiogravadas e transcritas para posterior análise das informações.

\section{PROCEDIMENTOS}

O acesso aos participantes se deu, primeiramente, por meio da apresentação da proposta de pesquisa para as instituições que trabalham com MSE de caráter fechado e aberto no município (etapa preliminar de pesquisa segundo a Resolução 510 de 2016 do Ministério da Saúde, 2016). Após aceite de cada uma delas, o projeto foi submetido na Plataforma Brasil para avaliação do Comitê de Ética da Universidade Federal de Santa Maria. Com a aprovação sob parecer n. ${ }^{\circ}$ 2.952.893 de 09 de outubro de 2018, foram realizados contatos com os psicólogos para apresentação do Projeto, esclarecimento de dúvidas e convidando-os para a participação na pesquisa. Após esse processo as entrevistas (todas realizadas no mês de outubro do ano de 2018) foram agendadas conforme disponibilidade de cada participante. Apesar de ter sido deixado em aberto a decisão sobre o local da entrevista, todos os participantes escolheram responder a entrevista no local e horário de trabalho.

Os aspectos éticos que protegem os participantes da pesquisa foram respeitados de acordo com a Resolução 510/2016 de ética na pesquisa, bem como a Resolução 466/2012 (Ministério da Saúde, 2013). A partir do convite realizado pela pesquisadora, todas as dúvidas acerca da pesquisa foram sanadas e então foram agendadas as entrevistas nas quais foi solicitada a assinatura do Termo de Consentimento Livre e Esclarecido. Ofereceu-se assistência ao participante da pesquisa caso necessário, compreendida aqui como aquela prestada para atender danos imateriais decorrentes, direta ou indiretamente, da pesquisa. A qual até o momento de desenvolvimento do presente estudo não foi solicitada por nenhum participante. Além disso, foi assegurado o direito de desistência em qualquer momento da pesquisa e feito o compromisso com a devolução dos resultados encontrados.

As informações coletadas foram analisadas qualitativamente conforme Bardin (2011). Neste estudo focou-se tanto nas respostas obtidas nas questões que se referiam diretamente a direitos humanos (identificando isso de forma explícita), como também as falas que traziam essas informações de forma implícita (sem usar termos específicos da área). A grande categoria aqui identificada como: A Socioeducação como ferramenta para garantir direitos humanos - busca a partir do que preconizam as legislações identificar o que os psicólogos que operacionalizam as MSE têm feito para garantir o que está preconizado e também o que os mesmos entendem como sendo uma prática de garantia de 
direitos humanos. As legislações utilizadas para buscar tal entendimento foram: a Declaração Universal dos Direitos das Crianças, a Declaração Universal dos Direitos Humanos, a Constituição do Brasil, o Estatuto da Criança e do Adolescente e o Sistema Nacional de Atendimento Socioeducativo.

\section{RESULTADOS E DISCUSSÃO}

\section{A SOCIOEDUCAÇÃO E A GARANTIA DE DIREITOS: A QUESTÃO DAS REPRESENTAÇÕES SOCIOCULTURAIS}

Nesta categoria foram analisados os impactos das representações socioculturais acerca dos adolescentes em cumprimento de MSE e consequentemente acerca das MSE a eles aplicadas sobre a promoção dos direitos. Buscou-se compreender como tais concepções acerca dos adolescentes em conflito com a lei estão interferindo no dia a dia de trabalho dos profissionais e no aspecto da garantia de direitos dessa população.

A discussão aqui apresentada introdutoriamente a respeito dos apelos da mídia e setores da sociedade em prol da redução da maioridade penal, foi um aspecto mencionado por todos os participantes da pesquisa como algo que influencia direta e negativamente no trabalho que as instituições desenvolvem. Conforme P4 narra: "...porque a mídia fala e a mídia nunca vai dizer assim que um adulto junto com um adolescente cometeu um assalto. Não... vai dizer que um adolescente comandou um adulto e fizeram o assalto". Souza, Paiva e Oliveira (2014) discutem sobre as políticas de atendimento a juventude e sobre enfoque privilegiado dos jovens pelo poder coercitivo do Estado e que isso não significa necessariamente que os jovens cometem mais ilegalidades, mas sim que estão mais associados às práticas tidas como ameaçadoras a segurança pública.

Quando tem, por exemplo, o apelo pra que tenha redução da maioridade penal, né, e de que se construa mais presídios, que é um pouco a onda que a gente tá vivendo hoje né. (...) aí é um certo incentivo de que é aqui mesmo que esses meninos tem que tá (P1).

Essa fala remete a ideia do encarceramento como estratégia para um tipo de 'higienização' das cidades. E que mostra que é possível que não se tenha superado totalmente algumas concepções advindas do período da Doutrina da Situação Irregular e do chamado "menorismo", compreendendo que a internação teria a função de reabilitar as crianças e adolescentes para o convívio social "normal", aceito pela sociedade (Figueiró, Minchoni, \& Mello, 2014). Colocar adolescentes que infringem as normas e legislações em Unidades de Internação pode, neste contexto, apontar para uma continuidade do processo de exclusão social, o mesmo que os leva para o cometimento do ato infracional.

Mudam-se as formas de conceituar e abordar as políticas de assistência à infância e juventude, porém a mudança de terminologia e aquilo que foi mudado na 
teoria (nas legislações) não garante efetivamente uma mudança de paradigma. Quer dizer, a forma de se referir a crianças e adolescentes pobres passa ter distintas expressões, como: carentes, em risco social, em situação de vulnerabilidade social, em situação de rua, em conflito com a lei. Porém, as expressões continuam a apontar para uma mesma população e acabam por manter o estigma social que as mesmas carregam. O que reproduz estratégias de contenção e controle muito semelhantes às anteriores a Doutrina da Proteção Integral. De fato, mesmo na vigência do ECA, algumas práticas continuam a fortalecer a crença em modelos hegemônicos, agora com nova roupagem (Scisleski, Gonçalves, \& Cruz, 2015). Ao invés de chamar os jovens que se encontram em situações diversas de desenvolvimento, que moram na rua ou que cometem ato infracional de menores, chama-se de jovem em situação de vulnerabilidade social, porém isso não garante uma mudança na forma de olhar pra eles. A mudança na forma de se referir é apenas um ponto que deve ser acompanhado da mudança do lugar social a eles oferecido. Quer dizer, são vivências de infâncias e juventudes diversas e que precisam ser percebidas em suas singularidades e contextos próprios e que precisam ser respeitadas. No caso dos adolescentes em cumprimento de MSE, deve-se ter a devida atenção a complexidade do fenômeno da violência associada a infração juvenil. O que P5 confirma com seu relato a respeito das atividades que desenvolve junto aos adolescentes em MSE: "...todos os profissionais se reúnem, e aí a gente vai discutir o caso. Vendo as particularidades do adolescente, da família, e vamos elaborar um plano individual de atendimento. Pra, né, pra dar esse suporte pro adolescente como um todo, né. Não é só chegar aqui, cumprir a medida, participar da orientação socioeducativa, não. É bem mais amplo, é bem mais complexo, né?"

Tendo em vista essa complexidade, fica claro que os apelos da mídia e as representações socioculturais que reforçam a ideia de periculosidade e de responsabilidade dos adolescentes pelas estatísticas de violência influenciam diretamente o andamento das MSE. As MSE necessitam da articulação de diferentes políticas públicas e setores da sociedade, tais representações podem dificultar o entendimento de que todos são corresponsáveis por esses jovens. P5 em resposta ao questionamento a respeito de como caracteriza o público atendido naquele serviço (Organização não Governamental que desenvolve MSEs) relatou que "Então, falta recursos, tem uma vulnerabilidade social bem dramática. Questões de acesso à saúde e tudo o mais é difícil, né. Tanto que tem o setor da saúde que tipo, tem adolescentes que nunca foram num dentista, nunca foram num postinho" (P5).

Campos e Cavalcante (2014) alertam para a reflexão de que as leis de proteção podem resultar como danosas para aqueles a quem se destinam. Isso porque consagram um sistema dual de atendimento, imputando a condição de menor aquelas crianças cujas famílias são ausentes ou não têm condições de prover o necessário para a vida, e considerando crianças aqueles cuja procedência familiar é tida como social e legalmente aceito. Fica a impressão de que a esses 
adolescentes são destinadas tão somente aquelas políticas específicas (Socioeducação), enquanto o acesso a políticas (de saúde, assistência social, educação...), que deveriam estar acessíveis a população em geral, eles efetivamente têm quando ingressam no sistema socioeducativo.

A mobilização da opinião pública é indicada pelo ECA no artigo 88 como fundamental para a efetiva elevação de crianças e adolescentes à condição de sujeitos de direitos (Presidência da República, 1990). O CONANDA coloca:

A discussão aprofundada e contínua com a população em geral, por meio dos diversos segmentos organizados, favorecerá a construção de uma sociedade mais tolerante e inclusiva, tendo em vista que sobre esses adolescentes recai grande parte da hostilidade e do clamor por maior repressão, o que tem gerado campanhas de incitação de desrespeito a princípios e direitos constitucionais atribuídos a esse público (CONANDA, 2006, p.31).

Essas ideias e informações propagandeadas pela mídia e sociedade acabam não oportunizando uma reflexão sobre o contexto todo que envolve um adolescente em cumprimento de MSE. O desconhecimento acerca das múltiplas facetas que compõem o caminho percorrido por esses adolescentes para chegar até o ato infracional dificulta a compreensão de que o êxito de uma MSE não é também uma tarefa simples. Quando questionado sobre os pontos negativos do trabalho na Socioeducação, P5 afirmou que "ainda há, sim, né... discriminação, preconceito, né, uma falta de entendimento das pessoas em relação à realidade de cada um e em termos de perspectivas de futuro, muita gente não acredita nas mudanças".

Assim, acaba-se reproduzindo um argumento simplista na qual "a segurança é entendida como a fórmula mágica de proteger a sociedade da violência produzida por desajustados sociais que precisam ser afastados do convívio social, recuperados e incluídos" (Volpi, 1997/2015, p. 11). Nesta mesma linha de argumentação não há qualquer problematização sobre o que isso significa ou mesmo sobre como fazê-lo. Desconsiderando também a cidadania, os direitos desses adolescentes e desqualificando-os. Petry e Nascimento (2016) concluem que frente aos discursos sobre a redução da maioridade penal, cabe à Psicologia - enquanto ciência e profissão - posicionar-se de modo a subverter às convocações em prol da manutenção da cultura punitiva e autoritária que visa ao engessamento de identidades, normalidades e moralidades, tanto no âmbito das políticas institucionais, quanto nas micropolíticas das relações sociais. Também Grassi, Coltro, Giacomozzi e Rosa (2019), em estudo sobre grupos do contexto socioeducativo, apontam que "o olhar da Psicologia sobre as dinâmicas subjetivas e inter-relacionais presentes no contexto de privação de liberdade de adolescentes se torna indispensável para a personalização da medida socioeducativa e para a expressão das potencialidades individuais desses jovens" (p. 238). O que fortalece a ideia de que a Psicologia, enquanto profissão, presente 
no desenvolvimento da política socioeducativa, tem o dever de primar pelos direitos dos jovens em cumprimento de MSE.

E essa falta de informação ou de ampliação da visão sobre o fenômeno pode estar abrindo margem para que a sociedade tenha uma ideia de que soluções simplistas são viáveis. Uma vez que se enxerga uma questão de forma simplista, sem questionar ou problematizar, as hipóteses de solução acabam tomando o mesmo rumo. As demandas da sociedade não levam em conta que a mudança na situação dos adolescentes decorre de processo complexo que demanda tempo e estrutura. Além disso, não levam em conta a história de vida do adolescente e o fato de que também ela, a sociedade, está envolvida nesse processo (Santos \& Menandro, 2017).

Essa dificuldade foi bastante exemplificada pelos participantes no que diz respeito à questão de acesso às escolas, ao direito garantido constitucionalmente à educação pública e de qualidade (Presidência da República, 1988). "como as escolas muitas vezes ficavam negando vagas, e as pessoas com esse receio de receber os meninos, os professores têm receio de receber os guris..." (P2) "dificuldade assim das escolas aceitarem os adolescentes. Quando eles estão cumprindo medida eles precisam estudar..." (P3). A escola é reconhecida pela oportunidade de distanciamento da realidade infracional, pela reinserção social e possibilidade de formação profissional para os adolescentes que cumprem MSE (Padovani \& Ristum, 2013). Sendo assim, para além de ser um direito básico das crianças e adolescentes é também uma responsabilidade do sistema socioeducativo, podendo atuar como um fator de proteção a essa população. Conforme o Sinase, os Planos de Atendimento Socioeducativo deverão, obrigatoriamente, prever ações articuladas nas áreas de educação, saúde, assistência social, cultura, capacitação para o trabalho e esporte, para os adolescentes atendidos (Presidência da República, 2012). Na busca de tais articulações, P1 relata a respeito das dificuldades de efetivar o trabalho em rede:

Tem muitas situações assim de bastante preconceito com relação aos meninos e dai a gente vai tentar organizar uma outra coisa, ou mesmo obter informações sobre a vida desse sujeito e dai o que pesa muito mais né, vem uma fala carregada de desimplicação assim... tipo, o que que tu ainda quer falando sobre isso... que não deu certo uma tentativa que a gente fez, não deu certo outra tentativa... e não deu certo e não deu certo. E não vai dar certo, né... assim, uma coisa meio desesperançosa.

Fica evidente que algumas instituições, como o exemplo das escolas, apresentam dificuldades de se compreenderem enquanto parte da rede de atendimento aos socioeducandos. Entende-se que isso seja, então, um reflexo da desinformação sobre a própria política e também uma consequência do que vem sendo noticiado e propagado a respeito da juventude que enfrenta a vulnerabilidade social e a negligência estatal. Além de as equipes escolares não terem momentos formativos a respeito desse trabalho junto aos adolescentes em cumprimento de 
MSE, também são bombardeadas com notícias e discursos políticos que revitimizam e caricaturam esses jovens. Discursos e notícias essas que resultam em medo não somente para os cidadãos em geral, mas também para os profissionais que trabalham com as políticas públicas e isso tem impacto direto no cotidiano de trabalho. Feffermann (2013) traz a constatação de que ocorre uma escamoteação dos dados da realidade, promovendo a violência como um produto rentável e aguçando a sensação de medo, tendo como consequência uma exigência quase que popular para o recrudescimento da intervenção punitiva.

Entretanto, os profissionais que trabalham nas políticas públicas devem buscar informações em fontes mais seguras e científicas, compreendendo que a violência é uma forma de expressão da desigualdade social. Aquilo que nomeamos como questão social resulta da conjugação de problemas políticos, sociais e econômicos cujos efeitos são detectáveis: a pobreza, a miséria ou a violência (Scisleski et al., 2015).

Dessa forma, os profissionais que se propõem a trabalhar com MSE acabam se deparando em diferentes situações com questões sociais complexas. Inclusive com o descompromisso de outras instituições para com os adolescentes em conflito com a lei. Conforme relato de P1: "Quando um adolescente chega pra gente e a gente tem poucas referências sobre ele, a gente liga pra alguém que ele falou que ele já esteve e a gente vai falar com o lugar e ou o profissional não conhece o menino ou tem que procurar no prontuário e aí o prontuário já não tá mais". Tal situação expõe a rotatividade dos profissionais em equipamentos das políticas públicas, a falta de informações nos prontuários, que pode ser gerada pela própria dinâmica do trabalho, ou ainda, pode denotar algo não pontual ou específico, ou mais facilmente trabalhado, como por exemplo, desgaste com o trabalho, que ocasiona certo descompromisso com o público para qual presta serviço. Não necessariamente por preconceito, mas principalmente por desconhecimento sobre o contexto socioeducativo e também sobre sua corresponsabilidade. Sobre isso o CONANDA (2006) aponta a necessidade de elaboração de uma política estadual e municipal de atendimento integrada com as demais políticas e também a capacitação dos atores socioeducativos. Com isso, poderiam tornar-se mais comuns momentos de troca e capacitação entre os serviços da rede de atendimento. P1 também relata a vulnerabilidade sentida pela ausência do estabelecimento de parcerias com os outros serviços da rede: "Mesmo quando a gente pensa algumas coisas e essas coisas dependem de outros serviços, a gente fica um pouco inseguro assim de se a gente vai conseguir".

Quanto à capacitação da equipe técnica, o Sinase já coloca a necessidade de ter uma formação em conformidade com as normas de referência do sistema socioeducativo e dos conselhos profissionais e com o atendimento socioeducativo a ser realizado (Presidência da República, 2012). Mas pensa-se que os serviços que devem trabalhar em colaboração com o Sistema 
Socioeducativo também precisam de um espaço para se inteirar daquilo que a socioeducação espera deles e também para refletir acerca das representações que carregam consigo a respeito da violência cometida por adolescentes.

Os dados aqui encontrados e discutidos vão ao encontro do que Volpi (1997/2015) encontrou em sua pesquisa quantitativa sobre os adolescentes em conflito com a lei privados de liberdade no Brasil, realizada em 1994. Neste estudo já são apontados três mitos acerca do fenômeno do ato infracional cometido por adolescentes: o hiperdirecionamento (considerar que os atos infracionais cometidos por adolescentes representam parcela muito significativa nos crimes cometidos no país); a periculosidade (apenas 19\% dos atos infracionais cometidos por adolescentes foram cometidos contra a pessoa humana) e o da irresponsabilidade penal (constatando que é falso dizer que os adolescentes não são responsabilizados pelos seus atos). Essas são questões que foram apontadas pelos psicólogos que constataram que tais ideias não estão fazendo parte apenas do imaginário social, mas elas estão presentes no dia a dia do trabalho desses profissionais e também se mostram influências no entendimento que outras equipes e outros setores têm sobre os adolescentes em conflito com a lei.

\section{A PRÁtICA SOCIOEDUCATIVA E A GARANTIA DE DIREITOS HUMANOS}

Nesta categoria foram analisadas as práticas desenvolvidas nas instituições socioeducativas que visam a garantir direitos dos adolescentes em conflito com a lei. Está análise foi composta não somente daquelas respostas dadas pelos psicólogos diretamente quando questionados sobre os direitos dos adolescentes, mas também aquilo que foi apontado por eles como parte do trabalho e que indiretamente diz respeito a promoção e garantia de direitos humanos. A análise, portanto, não se restringiu apenas às atividades desenvolvidas diretamente com os adolescentes, mas também ao trabalho que envolve a articulação com outros setores e políticas.

O acesso à educação foi um dos direitos mais citados pelos participantes tanto como uma das prioridades no plano de atendimento das MSE, quanto como uma das dificuldades encontradas no sentido de buscar a contrapartida das instituições escolares e não encontrar. $O$ que é bastante preocupante, pois a educação é um direito básico que precisa ser garantido e neste sentido fica evidente a dificuldade das escolas em reconhecer $\mathrm{o}$ adolescente em cumprimento de MSE enquanto um cidadão. Conforme já apontou Volpi (1997/2015, p. 12), "reconhecer no agressor um cidadão parece ser um exercício difícil e, para alguns, inapropriado". Mas para além do rótulo que algumas pessoas acabam colocando nos adolescentes em conflito com a lei, as instituições escolares não podem se basear nesse tipo de preconceito para negar vaga a um adolescente. Tratam-se de instituições públicas que devem atender a todos sem qualquer distinção. Conforme o ECA, a criança e o adolescente têm direito à 
educação, visando ao pleno desenvolvimento de sua pessoa, preparo para o exercício da cidadania e qualificação para o trabalho, assegurando-se-lhes, dentre outras coisas, o acesso à escola pública e gratuita próxima de sua residência (Presidência da República, 1990).

Neste cenário fica evidente que as equipes do sistema socioeducativo deste município vêm enfrentando dificuldades em contar com as escolas como parte da rede de atendimento ao adolescente em cumprimento de MSE. Pessoa e Coimbra (2017) alertam sobre a necessidade de que todos os contextos de desenvolvimento se engajem num processo contínuo de práticas e reflexões para garantir efetivação do desenvolvimento pleno desses sujeitos em suas máximas potencialidades. As instituições educacionais são parte importante na garantia e proteção dos direitos dos adolescentes e precisam se responsabilizar.

Na busca de encontrar uma solução para o problema apresentado, as equipes juntamente com o poder judiciário local buscaram promover um momento de diálogo e sensibilização com os representantes das escolas. Com objetivo de desmistificar algumas questões sobre quem são esses jovens e sensibilizar sobre a importância de a escola apoiá-los nesse momento complexo que é o de cumprimento de MSE. Conforme relatos:

...e então tinha essa queixa de algumas escolas terem dificuldade de aceitar esses adolescentes, então amanhã ele organizou, vai ter uma reunião com representantes das escolas que a gente mais matricula os jovens pra falar do nosso trabalho, apresentar nosso trabalho. Ele (o promotor de justiça) vai fazer uma fala, a escola vai fazer fala. Tudo isso pra gente poder estreitar as relações (P3).

Um psicólogo explica o contexto a partir do qual foi pensada a estratégia de articular um momento de discussão e troca entre as instituições socioeducativas e representantes das escolas:

como as escolas muitas vezes ficavam negando vagas e as pessoas com esse receio de receber os meninos os professores têm receio de receber os guris. (...) dai a gente fez esse encontro com as escolas, coordenado pelo promotor, ele encabeça essa história pra sensibilizar as escolas no momento de receber os meninos depois que eles saem daqui, não só quando saem daqui, mas também quando estão no [sigla que identifica a instituição], quando estão no [sigla que identifica a instituição] eles têm que estudar na comunidade, nas escolas da comunidade. E os meninos que estão cumprido [...] para que as escolas sejam mais receptivas, mais acolhedoras, porque se não tiver acolhimento os guris não vão ficar (P2).

O estudo de Seabra e Oliveira (2017) identificou que nas escolas há o receio de que a presença de adolescentes em cumprimento de MSE venha a perturbar o 
ambiente das salas de aula. Ao visar uma aproximação desses jovens ao contexto escolar, as mesmas autoras ressaltam que a relação entre escola e atores envolvidos no cumprimento da MSE não deve se restringir a encaminhamentos e fluxo de documentos, sendo fundamental o diálogo sobre a realidade dos adolescentes visando à construção de estratégias que ampliem suas possibilidades de escolarização. Essa necessidade apontada pelo estudo corrobora o que os profissionais participantes desta pesquisa buscaram desempenhar quando organizaram um momento de esclarecimentos, conscientização e troca de informações com as escolas do município.

Então, além da negligência, que pode ser percebida por parte das instituições educacionais deste município para com esses adolescentes, deve-se lembrar que a postura das escolas reflete também o quanto as mesmas se encontram com dificuldade em compor a rede de proteção. Os professores sofrem com sobrecarga de trabalho, um grande número de alunos e dificuldades quanto a condições de trabalho e necessidade de capacitação. A escola também compõe o grupo de atores importantes no desenvolvimento da prática socioeducativa e sua atuação deve agregar no desempenho das MSE.

O estabelecimento de formas de superação dos entraves que se colocam na prática socioeducativa exige capacitação técnica e humana permanente e contínua considerando, sobretudo, o conteúdo relacionado aos direitos humanos (CONANDA, 2006). Pode-se perceber que as equipes das instituições socioeducativas e o poder judiciário, neste caso, têm reunido esforços para fortalecer as relações com as escolas e ao mesmo tempo oferecer as mesmas um conhecimento acerca do trabalho desempenhado pela política socioeducativa. Entende-se que essa equipe, atuante no campo socioeducativo, vem trabalhando para alinhar alguns conceitos e concepções do trabalho com outros profissionais que podem e devem colaborar com a rede de atendimento, como é o caso das escolas, esclarecendo questões e desmistificando possíveis crenças que não correspondem ao que de fato é o trabalho na socioeducação.

A respeito, mais especificamente, das MSE de internação foi relatado que há superlotação na instituição. No momento da coleta de dados, havia o dobro de adolescentes do que é a capacidade. Uma/um participante relata que: "uma unidade com uma estrutura muito ultrapassada, uma unidade que tá inchada que a capacidade é pra 39 meninos e a gente tem o dobro de meninos" (P1). Esse tipo de fato é grave levando em conta o preconizado pelo Sinase, pois em todos os tipos de MSE tem-se uma atenção com o espaço físico adequado, mas no que tange a MSE de internação isso é ainda mais pontuado. Segundo o CONANDA (2006) um aspecto importante para o Sinase é a definição do número de adolescentes por unidade de internação, pois estes necessitam de um nível de atenção mais complexo dentro do sistema de garantia e defesa de direitos.

Além disso, o Sinase também traz em anexo um detalhamento técnico das normas, definições e etapas para elaboração e desenvolvimento de projetos 
arquitetônicos e complementares das Unidades de atendimento socioeducativo de internação e internação provisória. No anexo, tem-se toda uma especificação acerca da estrutura física das unidades, pensando desde a arquitetura, nas instalações e climatização. Todavia essa adequação não foi realizada na Unidade de Internação deste município, conforme relata P2: "A estrutura física, é como um... é a estrutura de um presídio assim, as grades, com os dormitórios né..." (P2) Então além da superlotação da Unidade, ela não está adequada ao preconizado pelo Sinase, o que dificulta a execução de muitas atividades importantes para o desenvolvimento das MSE's.

Tais restrições advindas da limitação do espaço físico foram mencionadas pelos profissionais, por exemplo: "A sala de grupos fica num lugar localizado onde os adolescentes dos dois setores (por que o [nome da instituição] é dividido em dois setores) os dois setores têm acesso visual pra essa sala. E isso dificulta pra que muitas pessoas de fora entrem aqui." (P1). A legislação aponta em seu $16^{\circ}$ artigo que a estrutura física da unidade deverá ser compatível com as normas de referência do Sinase (Presidência da República, 2012), e mesmo seis anos depois dessa reordenação do sistema de atendimento socioeducativo a referida Unidade ainda não tem planos de reforma da estrutura física. Conforme relatou P1: "é uma estrutura limitada. (...) Mas a gente sabe que isso despende recurso público. Isso não é fácil. Isso é demorado. Então eu acho que a gente vai ter essa limitação por um bom tempo ainda" (P1).

Nesse contexto, é importante apontar que a Unidade de Internação em questão está situada na região central do Estado e atende mais de vinte municípios. A Unidade se encontra com uma infraestrutura inadequada, além da superlotação. No período de coleta de dados contava com o dobro de adolescentes internos do que a capacidade, e no período de desenvolvimento da presente escrita contava com 69 internos sendo que a capacidade é para 39. Enquanto que a Unidade de Semiliberdade do município com capacidade para 25 adolescentes, contava com 6 adolescentes no mesmo período. Se, de acordo com a legislação, a medida em meio fechado deverá ser a última alternativa (caráter de excepcionalidade), porque superlotar a Unidade de Internação enquanto a de Semiliberdade dispõe de vagas? Uma hipótese é a de que todos os 69 adolescentes haviam cometido atos infracionais graves; como homicídio, latrocínio ou estupro. Entretanto, um detalhe importante é o de que 42,9\% dos adolescentes que estão no sistema socioeducativo no Estado tem como ato infracional o roubo. (Fonte: Assessoria de gestão e informação - Fase, online, dados de Jan-Mar, 2019).

Pensando nos objetivos do trabalho desempenhado por essas equipes com os adolescentes em MSE, os psicólogos participantes desta pesquisa demonstraram um ponto de vista comprometido em garantir que os jovens em situação de cumprimento de MSE não tenham seus direitos básicos infringidos e tenham a oportunidade de superar essa fase levando com eles um aprendizado. Foi mencionado que o comprometimento com os serviços prestados aos 
adolescentes dentro das instituições (no sentido da frequência, das combinações, pontualidade e qualidade) podem ser uma forma de respeitar os adolescentes enquanto cidadãos e viabilizar uma construção de vínculos de confiança entre os técnicos e os adolescentes. Conforme relatado: "Uma das coisas que nos faz estabelecer um vínculo de forma bastante rápida é a responsabilidade com os nossos horários pra atendê-los por que nós prezamos muito por agendar horários e chamá-los nesses horários" (P4).

E mesmo que a MSE seja uma imposição, que ela possa oferecer uma oportunidade de mudança real para o futuro desses meninos. "Nós entendemos que esse período de cumprimento de MSE é uma chance que nós temos pra oferecer novas perspectivas" (P4). Buscando, na medida do possível, oferecer a cada adolescente um atendimento que faça sentido para ele e que atenda às suas necessidades individuais. P4 coloca: "...o que é importante pra mim não é importante pra eles" (P4). Para atingir essa perspectiva é imprescindível conhecer e analisar cada situação, cada jovem, se despindo das próprias concepções de mundo e valores. Quer dizer: "o básico de tudo é conhecer bem esse contexto, conhecer bem a realidade deles, conhecer bem eles, pra aí entender de que forma a gente pode ter mais êxito no encaminhamento, nos atendimentos, nesse período que nós temos pra proporcionar um bom atendimento dessas questões" (P4). Se assim não for feito, corre-se o risco de que se esteja fazendo um jogo de reprodução de modelos de forma a serializar e fixar identidades a partir de modos de vida hegemônicos (Macedo \& Dimenstein, 2012). O que não seria respeitar esses adolescentes nas suas individualidades, seus desejos e realidades de vida.

Essa perspectiva é de suma importância, além de muito complexa. Isso por que é complexo adequar uma medida que é punitiva (no sentido que existe para reparar um dano cometido), mas que deva criar condições para a não reincidência (o que é como dizer que deve-se operar um reordenamento dos valores e padrões de conduta do sujeito transgressor) e ainda chamá-la de socioeducativa (Francischini \& Campos, 2005). Pode-se dizer que existe uma expectativa quanto ao que se espera de um adolescente durante e após o cumprimento da $\mathrm{MSE}$, pois a própria legislação já dá alguns indícios disso: estudar, buscar uma profissão, convivência familiar, tudo isso mostra uma certa concepção e padrão de sujeito.

Assim, entende-se que o período de cumprimento de MSE é um momento no qual o jovem deve ter acesso aos seus direitos, como: ter atenção à saúde, ter acesso a escola, ter sua documentação em dia, dentre outros. Mas é preciso pensar no depois, não somente na perspectiva da não reincidência do ato infracional, mas do acesso aos seus direitos básicos e de um lugar social de não exclusão. Sobre esses direitos e acessos, P5 aponta que "também é oferecido (...) encaminhamento pra identidade, documento (...). Questão de dúvidas jurídicas e tudo o mais, tem esse suporte com a nossa advogada". Também há um trabalho voltado para o mercado de trabalho e oportunidades tanto para os adolescentes 
como para suas famílias: "a gente tem o trabalho de fazer currículo, carteira de trabalho, encaminhar pra vagas de trabalho, o familiar dele também pode vir aqui, né, e fazer seu currículo. E aí a gente de acordo com o perfil quando surge vagas e tudo a gente encaminha aquela pessoa pra entrevista e tudo o mais" (P5).

Além disso, a sociedade muito espera do período de cumprimento de MSE pois há nas entrelinhas uma expectativa de que esse período vai mudar totalmente o adolescente e vai adequá-lo ao que a sociedade em geral tem como adequado socialmente. Entretanto, é preciso respeitar a história, as concepções e a realidade do adolescente, visto que após a MSE ele vai se deparar novamente com muitas questões não resolvidas, com ausências de diferentes gêneros. Assim, deve-se buscar desenvolver com o adolescente mecanismos para enfrentar situações adversas e apontar caminhos que podem ser úteis para construção de uma autonomia para que eles possam por si mesmos buscar seus direitos. Que possam dar continuidade aquilo que a MSE buscou proporcionar a eles.

Nessa perspectiva, os psicólogos entrevistados nesta pesquisa também apontaram que entendem a importância de envolver as famílias no processo de cumprimento da MSE e que os serviços dispõem desse trabalho de alguma maneira. No caso das instituições que executam MSE de restrição de liberdade, esse acompanhamento se dá por meio de visitas domiciliares e também pela inserção da família dos círculos de desligamento do adolescente. Além dos momentos de visita nos quais os familiares podem conversar e saber sobre o andamento da MSE dos filhos. Enquanto as instituições que executam MSE em meio aberto, acabam podendo oferecer outros tipos de serviço as famílias, conforme relato: "Os familiares eles podem participar das oficinas, tá? E também é oferecido atendimento psicológico. Encaminhamento pra identidade, documento e tudo o mais os familiares também podem usar desse serviço com o serviço social" (P5).

Diante disso, entende-se que os profissionais da psicologia estão buscando estabelecer estratégias de trabalho que venham a alcançar o máximo de concordância entre o estabelecido na legislação e o dia a dia do trabalho. Foi possível reconhecer nos relatos dos participantes uma preocupação em proporcionar direitos aos adolescentes, mesmo que nem sempre tenham identificado algumas de suas atuações, necessariamente, como atuação em direitos humanos. Também foi possível reconhecer uma preocupação com o futuro desses meninos, tentando fortalecer as famílias e apontar caminhos viáveis para que os adolescentes possam dar continuidade nas suas vidas longe do envolvimento com atos infracionais.

\section{CONSIDERAÇÕES FINAIS}

A atuação profissional no contexto socioeducativo tem sido permeada pelo olhar negativo das concepções sociais e culturais a respeito dos adolescentes em cumprimento de MSE e dos seus direitos. Concepções sociais e culturais infladas 
pelas informações advindas da mídia e dos discursos políticos que têm tentado disseminar ideias hiperdirecionadas acerca desses sujeitos. Excluindo-os do lugar de cidadãos e de sujeitos em situação peculiar de desenvolvimento e colocandoos em um lugar de preconceito e culpabilização por estatísticas que não são resultados dos atos infracionais cometidos por eles. Essas concepções têm adentrado algumas políticas e setores da sociedade que deveriam estar protegendo esses adolescentes e contribuindo com a política socioeducativa. Combater essa questão e levar informações verídicas, capacitando e conscientizando os profissionais e a sociedade é uma prática que tem se incorporado ao trabalho do psicólogo na socioeducação.

Conclui-se assim que na concepção dos participantes as representações socioculturais a respeito dos direitos humanos e dos adolescentes em cumprimento de MSE vêm interferindo de forma negativa no desenvolvimento do trabalho socioeducativo, na medida em que esse desafio se incorpora as demandas de trabalho. Isto é, os profissionais acabam precisando lutar por serviços que deveriam ser oferecidos naturalmente aos adolescentes e isso recai na qualidade das MSE oferecidas. É preciso abdicar de e/ou adiar outras atividades para buscar apoio de serviços que deveriam estar de portas abertas a esses adolescentes.

A expectativa pouco realista de que a MSE precisa adequar o adolescente aquilo que é a expectativa da sociedade sobre como deve se comportar e o que deve fazer da sua vida também acaba pesando na atuação dos psicólogos neste contexto de trabalho. Essa expectativa deriva de ideias e concepções, presentes no imaginário social, sobre essa população, de que os mesmos representam perigo e não são responsabilizados pelos seus atos. O que não condiz com a realidade, pois a perspectiva de responsabilização é presente nas MSE e disso é importante salientar que os atos infracionais cometidos por adolescentes não são, em sua maioria, violências contra a pessoa humana.

Assim, entende-se que prática psicológica não deve ser submetida a servir a normatização dos sujeitos e expectativas pouco realistas sobre os adolescentes em cumprimento de MSE, nem buscar a sua respectiva inserção nos modos de produção atuais. Mas sim, proporcionar acesso aos direitos fundamentais, respeitando a população atendida na sua realidade social e cultural e suas peculiaridades. O que pode não ser, também, um objetivo simples de ser alcançado, visto que a Política de Socioeducação nem sempre oferece as equipes recursos e viabilidade de executar aquilo que está preconizado no Sinase.

Sobre garantir os direitos que são devidos aos adolescentes em cumprimento de MSE ficou evidente que os psicólogos têm se empenhado em articular sua prática em consonância com tais necessidades. Atuando de forma intersetorial em prol de garantir acesso à políticas públicas, como assistência social, saúde e educação com qualidade, buscando inclusive tornar as instituições escolares parceiras das instituições socioeducativas. Os psicólogos demonstraram que mesmo com 
dificuldades teóricas, tem se esforçado para adequar sua prática profissional às necessidades dos adolescentes.

Os psicólogos também se mostraram engajados na tarefa de trabalhar com as famílias dos adolescentes atendidos, entendendo que para além de ser parte do preconizado pelo Sinase, é fundamental no aspecto de facilitar as perspectivas de vida após cumprimento da MSE. Percebe-se que os psicólogos buscam no seu trabalho com os adolescentes, tratá-los com respeito e com a prioridade que thes é devida. O que foi apontado pelos mesmos como uma forma de estabelecer bons vínculos e ofertar um serviço de qualidade.

Salienta-se que a realidade de algumas das instituições que compõem a rede de atendimento socioeducativo da cidade não está de acordo com as premissas do Sinase em termos de estrutura física, de materiais necessários e há superlotação na unidade de internação. Entretanto, os esforços dos profissionais auxiliam muito para que as MSE neste município não violem direitos.

Para pesquisas futuras, pensa-se que seria importante conhecer a visão de outras categorias profissionais sobre essa rede de atendimento. Já que esse estudo mostra um recorte daquilo que pensa e desenvolve a Psicologia neste contexto. Outro aspecto que merece atenção para futuras pesquisas é conhecer as impressões que outras políticas sociais têm do desenvolvimento das MSE e como as mesmas percebem sua responsabilidade neste contexto.

\section{REFERÊNCIAS}

Bardin, L. (2011). Análise de conteúdo (L. A. Reto \& A. Pinheiro, Trans.). Lisboa: Edições 70. (Trabalho original publicado em 1977).

Campos, H. R., \& Cavalcante, C. P. (2014). O adolescente e o estatuto jurídico: Transgressão e lei no Brasil. In I. L. Paiva, C. Souza, \& D. B. Rodrigues (Eds.), Justiça juvenil: Teoria e prática no sistema socioeducativo (pp. 33-48). Natal, RN: EDUFRN.

Conselho Federal de Psicologia - CFP. (2003). Os Direitos Humanos na Prática Profissional dos Psicólogos. Brasília: Coordenação Técnica CFP.

Conselho Federal de Psicologia - CFP. (2006). Direitos Humanos: um retrato das unidades de internação de adolescentes em conflito com a lei. Relatório das visitas realizadas simultaneamente em 22 estados brasileiros e no Distrito Federal, $2^{\text {a }}$ Edição. Brasília.

Conselho Federal de Psicologia - CFP. (2010). Referências técnicas para atuação de psicólogos no âmbito das medidas socioeducativas em unidades de internação. Brasília.

Conselho Nacional do Ministério Público (CNMP). (2013). Relatório da Infância e Juventude Resolução $n^{\circ}$ 67/2011: Um olhar mais atento às unidades de internação e semiliberdade para adolescentes. Brasília: Conselho Nacional do Ministério Público.

Conselho Nacional dos Direitos da Criança e do Adolescente [CONANDA]. (2006). Sistema Nacional De Atendimento Socioeducativo -SINASE/ Secretaria Especial dos Direitos Humanos Brasília-DF.

Cruz Neto, O., \& Moreira, M. R. (1999). A concretização de políticas públicas em direção à prevenção da violência estrutural. Ciência \& Saúde Coletiva, 4(1),33-52. http://dx.doi.org/10.1590/S1413-81231999000100004

Feffermann, M. (2013). Criminalizar a juventude: Uma resposta ao medo social. In: I. L. Paiva, M. A. Bezerra, G. S. N. Silva, \& P. D. Nascimento (Eds.), Infância e Juventude em contextos de vulnerabilidades e resistências (pp. 57-75). São Paulo: Zagodoni.

Figueiró, M. E. S. S., Minchoni, T., \& Mello, L. C. A. (2014). Políticas Públicas para crianças e adolescentes no Brasil: Um resgate histórico. In: I. L. Paiva, C. Souza, \& D. B. Rodrigues 
(Eds.), Justiça Juvenil: Teoria e Prática no Sistema Socioeducativo (pp. 19-32). Natal, RN: EDUFRN.

Francischini, R., \& Campos, H. R. (2005). Adolescentes em conflito com a lei e medidas socioeducativas: Limites e (im)possibilidades. PSICO, 36(3), 267-273. Recuperado em 17 de maio de 2018, de https://revistaseletronicas.pucrs.br/ojs/index.php/revistapsico/article/view/1397

Grassi, G. O., Coltro, B. P., Giacomozzi, A. I., \& Rosa, T. R. S. (2019). O trabalho do psicólogo com grupos de adolescentes em privação de liberdade. Estudos Interdisciplinares em Psicologia, 10(3), 228-242. http://dx.doi.org/10.5433/2236-6407.2019v10n3p228

Instituto de Pesquisa Econômica Aplicada - IPEA. (2015). Nota Técnica No 20. O adolescente em conflito com a lei e o debate sobre a redução da maioridade penal: esclarecimentos necessários. Brasília. Recuperado em 09 de dezembro de 2017, de http://repositorio.ipea.gov.br/handle/11058/5696

Macedo, J. P., \& Dimenstein, M. (2012). O trabalho do psicólogo nas políticas sociais no Brasil. Avances en Psicolicologia Latinoamericana, 30(1) 182-192. Recuperado em 20 de março de 2019, de https://www.redalyc.org/articulo.oa?id=799/79924085014

Mello, S. L. (1999). Estatuto da Criança e do Adolescente: É possível torná-la uma prática psicológica? Psicologia USP, 10(2), 39-151. https://doi.org/10.1590/S010365641999000200010

Ministério do Desenvolvimento Social e Agrário [MDSA]. (2016). Caderno de Orientações Técnicas: Serviço de Medidas Socioeducativas em Meio Aberto. Brasília, Distrito Federal: Secretaria Nacional de Assistência Social.

Minayo, C. de S. (1994). Pesquisa Social: Teoria, método e criatividade. Petrópolis: Vozes.

Ministério da Saúde. Conselho Nacional de Saúde. (2013). Resolução No 466/2012. Aprova diretrizes e normas regulamentadoras de pesquisas envolvendo seres humanos. Recuperado de https://conselho.saude.gov.br/resolucoes/2012/Reso466.pdf

Ministério da Saúde. Conselho Nacional de Saúde. (2016). Resolução $N^{\circ}$ 510/2016. Diretrizes e normas regulamentadoras de pesquisas envolvendo seres humanos em ciências humanas e sociais. Decreto $n^{\circ} 93.933$ de 12 de novembro de 1991. DOU n 98, seção 1, p. 44-46. Recuperado https://bvsms.saude.gov.br/bvs/saudelegis/cns/2016/res0510_07_04_2016.html

Organização das Nações Unidas (ONU). (1948). Declaração universal dos direitos humanos. adotada e proclamada pela Assembleia Geral das Nações Unidas (resolução 217 A III) em 10 de dezembro 1948. Recuperado em 10 de janeiro de 2019, de https://www.unicef.org/brazil/declaracao-universal-dos-direitos-humanos.

Organização das Nações Unidas (ONU). (1959) Declaração universal dos direitos das crianças adotada pela Assembléia das Nações Unidas de 20 de novembro de 1959. Recuperado em 10 de janeiro de 2019, de http://www.direitoshumanos.usp.br/index.php/Crian\%C3\%A7a/declaracao-dos-direitos-dacrianca.html

Padovani, A. S., \& Ristum, M. (2013). A escola e a construção da identidade de adolescentes autores de ato infracional. Revista Entreideias, 2(1), 151 -167. http://dx.doi.org/10.9771/23171219rf.v2i2.7672

Paiva, I. L., Gomes, R. C. A., \& Valença, D. A. (2016). Sistema Socioeducativo Potiguar: Um debate sobre violações de direitos de crianças e adolescentes em âmbito internacional. Revista de Direitos e Garantias Fundamentais, 17(2), 327-352. https://doi.org/10.18759/rdgf.v17i2.798

Pessoa, A. S. G., \& Coimbra, R. M. (2017). Redes de proteção para jovens em situação de risco: Construindo estratégias a partir de práticas bem sucedidas. In M. de F. P. Alberto, I. L. Paiva, \& B. M. Castro (Eds.), Intervenções com crianças, adolescentes e jovens em contextos de vulnerabilidade e desenvolvimento (pp. 213-232). Natal, RN: Caule de Papiro.

Petry, H., \& Nascimento, D. M. (2016). "Tá com dó? Leva pra casa!" Análise dos discursos favoráveis à redução da maioridade penal em rede social. Psicologia: Ciência e Profissão, 36(2), 426438. https://doi.org/10.1590/1982-3703001562014

Presidência da República. Casa Civil. Subchefia de assuntos jurídicos. (1988). Constituição Federal de 1988. Brasília- DF, Senado. Recuperado em 05 de março de 2018, de http://www.planalto.gov.br/ccivil_03/constituicao/constituicao.htm 
Presidência da República. Casa Civil. (1990). Lei No 8.069, de 13 de julho de 1990. Dispõe sobre o Estatuto da Criança e do Adolescente e dá outras providências. Brasília, DF. Recuperado em 10 de abril de 2018, de http://www.planalto.gov.br/ccivil_03/leis//8069.htm

Presidência da República. Casa Civil. (1993). Emenda Constitucional n¹7. Altera a redação do art 228 da Constituição Federal (imputabilidade penal do maior de dezesseis anos). Brasília, DF. Recuperado em 10 de janeiro de 2019, de http://imagem.camara.gov.br/Imagem/d/pdf/DCD27OUT1993.pdf\#page $=10$

Presidência da República. Casa Civil. (2010). Emenda Constitucional n65, de 13 de Julho de 2010. Altera a denominação do capítulo VII do Título VIII da Constituição Federal e modifica o seu art. 227, para cuidar dos interesses da juventude. Brasília, DF. Recuperado de http://www.planalto.gov.br/ccivil_03/constituicao/emendas/emc/emc65.htm

Presidência da República. Casa Civil. (2012). Lei federal n. 12.594, 18 de janeiro de 2012. Institui o Sistema Nacional de Atendimento Socioeducativo (Sinase), regulamenta a execução das medidas socioeducativas destinadas a adolescente que pratique ato infracional e dá outras providências. Brasília, DF. Recuperado de http://www.planalto.gov.br/ccivil_03/_ato20112014/2012/lei//12594.htm

Presidência da República. Casa Civil. (2013). SDH/PR (Secretaria dos Direitos Humanos). Plano Nacional de Atendimento Socioeducativo: diretrizes e eixos operativos para o SINASE. Brasília, DF: Secretaria de Direitos Humanos da Presidência da República. Recuperado de http://www.sdh.gov.br/assuntos/criancas-e-adolescentes/programas/sist

Presidência da República. Casa Civil. (2015). Proposta de Emenda Constitucional n¹15. Altera a redação do art. 288 da Constituição Federal. Recuperado de https://www25.senado.leg.br/web/atividade/materias/-/materia/122817/pdf

Santos, M. N. dos., \& Menandro, M. C. S. (2017). Atuação profissional junto aos adolescentes em medida socioeducativa de internação: Um estudo com psicólogos. Interação Em Psicologia, 21(2), 107-117. http://dx.doi.org/10.5380/psi.v21i2.34081

Scisleski, A. C. C., Gonçalves. H. S., \& Cruz, L. R. (2015). As práticas de Psicologia nas políticas públicas de assistência social, segurança pública e juventude. Revista de Ciências Humanas, 49(2), 60-74. https://doi.org/10.5007/2178-4582.2015v49n2p60

Seabra, R. C. F. F., \& Oliveira, M. C. S. L. (2017). Adolescentes em atendimento socioeducativo e escolarização: Desafios apontados por orientadores educacionais. Psicologia Escolar e Educacional, 21(3), 639-647. https://doi.org/10.1590/2175-353920170213111144

Secretaria Especial de Direitos Humanos - SEDH \& Fundo das Nações Unidas para a Infância [UNICEF]. (2007). Porque dizer não à redução da maioridade penal. Brasília, DF: Secretaria Especial dos Direitos Humanos. Recuperado de https://crianca.mppr.mp.br/arquivos/File/idade_penal/unicef_id_penal_nov2007_completo. pdf

Silva, M. V. O. (2005). A psicologia, os psicólogos e a luta pelos direitos humanos: Da ação a reflexão. In Conselho Federal de Psicologia (Ed.), Psicologia e direitos humanos: Educação inclusiva - Direitos Humanos na Escola (pp. 13-38). São Paulo, SP: Casa do Psicólogo.

Silva Junior, N. G. S. E., \& Garcia, R. M. (2017). Proposta de redução da maioridade penal: A prisão como vingança e equívoco social. Revista Eletrônica Espaço Acadêmico, 17, 131-142. Recuperado https://periodicos.uem.br/ojs/index.php/EspacoAcademico/article/view/36000

Souza, C., Paiva, I. L., \& Oliveira, I. F. (2013). Que política é essa? Um olhar sobre as políticas de juventude no Brasil. In I. L. Paiva, M. A. Bezerra, G. S. N. Silva, \& P. D. Nascimento (Eds.) Infância e Juventude em contextos de vulnerabilidades e resistências (pp. 77-99). São Paulo, SP: Zagodoni.

Valença, D. A., Lima, D. de F., \& Paiva I. L. (2014). A redução da maioridade penal: Entre a política pública e a barbárie. In I. L. Paiva, C. Souza, \& D. B. Rodrigues (Eds.), Justiça juvenil: Teoria e prática no sistema socioeducativo (pp. 59-77). Natal, RN: EDUFRN.

Volpi, M (2015). O adolescente e o ato infracional. (10ª ed.). São Paulo, SP: Cortez. (Trabalho original publicado em 1997).

Zamora, M. H. (2014). Prefácio. In I. L. Paiva, C. Souza, \& D. B. Rodrigues (Eds.), Justiça juvenil: Teoria e prática no sistema socioeducativo (pp. 11-16). Natal, RN: EDUFRN. 


\section{AGRADECIMENTOS}

As autoras agradecem a Coordenação de Aperfeiçoamento de Pessoal de Nível Superior (CAPES) pelo apoio financeiro por meio do Programa Nacional de Cooperação Acadêmica (PROCAD/ Edital 071/2013).

\section{CONFLITOS DE INTERESSES}

Não há conflitos de interesses.

\section{FINANCIAMENTO}

Esta pesquisa recebeu apoio financeiro por meio do Programa de Cooperação Acadêmica (PROCAD/ Edital 071/2013).

\section{SOBRE AS AUTORAS}

Bianca Zanchi Machado é psicóloga pela Universidade Franciscana (UFN), Mestre e Doutoranda em Psicologia pela Universidade Federal de Santa Maria (UFSM).

E-mail: biancaz.machado@gmail.com

(2) https://orcid.org/0000-0003-1627-5626

Samara Silva dos Santos é psicóloga pela Universidade do Vale do Rio dos Sinos (UNISINOS), Mestre e Doutora em Psicologia pela Universidade Federal do Rio Grande do Sul (UFRGS). Atua como docente do Programa de Pós-graduação em Psicologia da Universidade Federal de Santa Maria (UFSM).

E-mail: samara.santos@ufsm.br

(2) https://orcid.org/0000-0002-7171-5113 